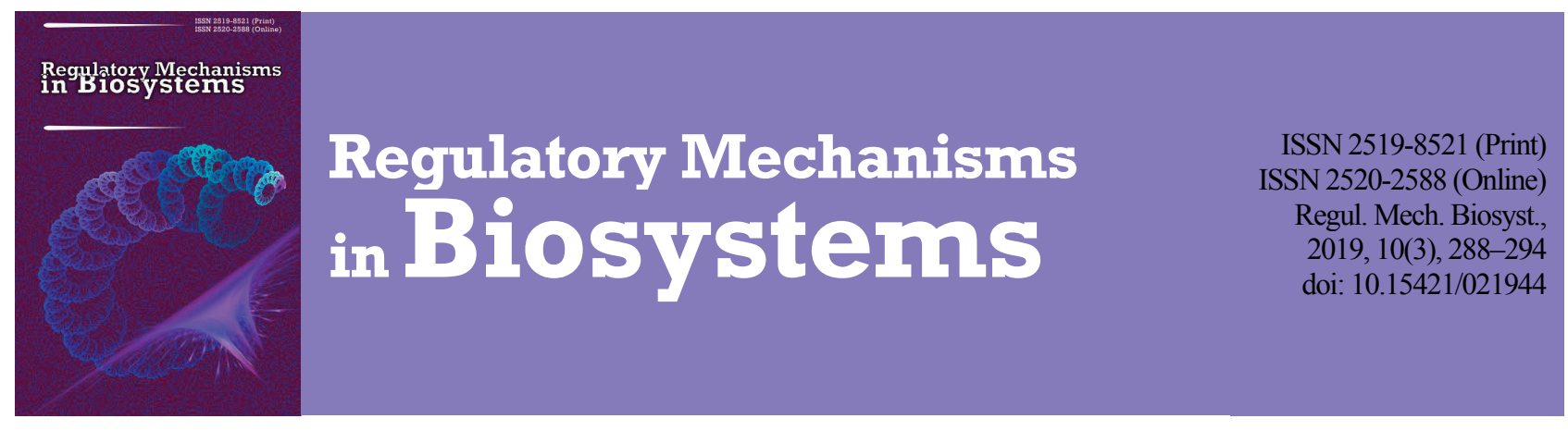

\title{
Age peculiarities of interaction of motor and cognitive brain systems while processing information of different modality and complexity
}

\author{
V. S. Lyzohub*, N. P. Chernenko*, T. V. Kozhemiako*, A. A. Palabiyik**, S. V. Bezkopylna* \\ *Cherkasy Bohdan Khmelnytsky National University, Cherkasy, Ukraine \\ **Ardahan University, Ardahan, Turkey
}

Article info

Received 01.07.2019

Received in revised form 26.07 .2019

Accepted 30.07.2019

Cherkasy Bohdan Khmelnytsky National University Shevchenko bl., 81, Cherkasy 18000, Ukraine.

Tel.: +38-067-757-08-30.

E-mail:vlizogub@ukr.net

Ardahan University, Ardahan, Turkey.

Tel.: +38-063-998-33-15

E-mail:

aalperenp@hotmail.com

Lyzohub, V. S., Chernenko, N. P., Kozhemiako, T. V., Palabiyik, A. A., \& Bezkopylna, S. V. (2019). Age peculiarities of interaction of motor and cognitive brain systems while processing information of different modality and complexity. Regulatory Mechanisms in Biosystems, 10(3), 288-294. doi:10.15421/021944

The interaction of motor and cognitive brain systems while performing the tasks of processing information of different modality and complexity is an important component of the brain's integrative activity, which provides the individual adaptation of a person to changing environmental conditions. 116 individuals participated in the research; there were right-handed children aged 7-8, adolescents aged 11-12 and 15-16, and young men aged 19-20 among them. The investigated individuals performed a cognitive task, which included determining the modalities of a signal, the shape of a figure, the meaning of a word, and the fast and error-free reaction of differentiation with left (goL) or right (goR) hand or inhibition of motor action (nogo). The motor task involved a quick reaction to signals of different modality in the go/go/go mode. The results show that in the ontogenesis, the interaction of motor and cognitive brain systems gradually increases during processing of information of different modality and complexity by children, adolescents and young people. Closer functional interaction of motor and cognitive brain systems according to the indicators of speed and success of performing both tasks was found to be greater in the young men aged 19-20 and the adolescents aged 15-16 and 1112 than in the children aged 7-8. The investigated individuals with the high-speed level of performing cognitive tasks were characterized with reliably higher indicators of motor reactions. Correlation analysis confirmed the statistically significant relationship between the speed characteristics of the motor and cognitive functional systems of the brain. The age dynamics of functional interaction between the motor and cognitive systems, as well as the speed and success of performing tasks depended on the mode selection of information processing. The success and speed of performing different variants of motor tasks in the go/go/go mode were higher in all age groups than in the conditions of the combined motor and cognitive tasks while differentiating goL/nogo/goR. The functional interaction of motor and cognitive brain systems in children, adolescents and young men while processing information increased gradually and depended on the modality of signals. The speed and success of results of performing motor and cognitive tasks were higher than for imaginative signals, and lower than for verbal ones for all age groups. Left-brain dominance of functional asymmetry was found for the cognitive systems. The number of mistakes on words was always less and the reaction speed was higher for the right hand than for the left one in the goL/nogo/goR mode. Asymmetry was weaker in the children aged 7-8 for the combined tasks using imaginative stimuli, and statistically significant in the groups of adolescents aged 11-12 and young men aged 15-16 and 19-20 for verbal signals presented in the goL/nogo/goR mode. The research results and methods can be used for the prognostic estimate of human activity in the conditions of complex information loads and neurodegenerative diseases.

Keywords: ontogenesis; sensory-motor integration; information processing; differentiation of stimuli; switching attention; imaginative and verbal signals; interference, asymmetry.

\section{Introduction}

Science of the brain in the 21 st century is considered to be the fundamental basis of all types of intellectual activity and everything connected with the development of man and personality, education, study, language and culture, as was stressed at 2019 plenary meeting of the XX Congress of the Ukrainian P. H. Kostiuk Physiological Society. However, the knowledge of the brain's work in the sphere of behaviour, social systems, economy, culture, history, art, etc. is not sufficient. The brain is known to perceive, process and store a lot of information in memory, on the one hand, and to generate information itself on the other hand. Therefore, research on the integrative function and interaction of different brain systems while processing information of various modality and complexity is topical issue of mental activity physiology.

It is known that a characteristic feature of the present time is the significant increase of the impact of various types of information load on a person. The widespread use of computers in the educational pro- cess promotes opportunities to master the information space by students, which requires optimization of the educational process in order to increase its efficiency and to maintain users' health. The perspectives of optimization of education using information technologies determine the relevance of studying physiological support of purposeful activities of children, adolescents and young adults. There are two directions of this research. The first one deals with the problem of the computer's impact on the human body, the second one concerns the determination of physiological and psychological factors that stipulate the individual peculiarities of efficient processing of information. Literature analysis shows that most research on information processing mechanisms taking into account the features of higher mental functions is performed on individuals of mature age (Luria, 2004; Van der Elst et al., 2006; Kostandov, 2010; Makarchuk et al., 2011). Age-related changes in information processing and the interaction of the motor and cognitive brain systems while performing tasks of different complexity and modality in children, adolescents and young men are studied insufficiently. The investigation 
of age-related changes in functioning motor and cognitive brain systems while performing complex information tasks is extremely necessary for finding the mechanisms for the development of an individual's higher mental functions and mental activity in ontogenesis, serving as a basis for their correction (Kostenko \& Lokteva, 2000; Rusalova, 2003; Makarenko \& Lyzohub, 2011).

In recent years, stop - signal and go/no - go models (Verbruggen \& Logan, 2008) including simultaneous performance of motor and cognitive tasks have been widely used in psychophysiology and rehabilitation to discover the integrative functions of the brain. Different variants of two- and three-stimulus tasks are described which study the interactions of motor and cognitive brain systems (Luria, 2004; Hiraga et al., 2009; Makarenko \& Lyzohub, 2018). Tasks on calculating, pronouncing words, singing (Horak, 2006; Schulz et al., 2011), determining colours, object types and shapes or meaning of a word (Haggard \& Cockbum, 1998; Low et al., 2009; Makarenko et al., 2011) are used as a cognitive component of processing complex information. Motor tasks consist of walking, purposeful movement by hand or foot, holding posture, hitting a target (Sperry, 1980; Maurer et al., 2006; Fraizer \& Mitra, 2008; Furley \& Memmert, 2010), as well as studying the speed of simple sensorymotor reactions (Makarenko \& Lyzohub, 2011). To study the interaction of motor and cognitive systems, the method of differentiation while performing a two-stimulus test of go/nogo (Glantz, 1998; Zhavoronkova et al., 2011; Bekhtereva et al., 2015) is used. The use of double tasks becomes useful in the diagnostics of patients with Alzheimer's disease, Parkinson's disease and in the evaluation of risks for people working in the extreme conditions occurring in real life situations (Dempsey \& Morgan, 2015). The three-stimulus test of differentiating stimuli in goL/nogo/goR paradigm (Makarenko et al., 2011; Lyzohub et al., 2018) is offered as a model of complex information tasks of processing signals of different modality requiring constant interaction of the motor and cognitive systems, switching attention, processing signals in memory. Different models show that qualitative level of sensory-motor integration of the brain can be determined by the indicators of reaction accuracy (the number of mistakes or the variability of response time); reaction speed is its quantitative characteristic (Kamenskaya et al., 2015). Processing complex information of different modality in the differentiation mode of goL/nogo/goR and switching attention will probably be accompanied by different alterations in the interaction of the cognitive and motor brain systems, as well as quantitative and qualitative characteristics of sensory-motor integration in children, adolescents and young adults.

The goal of the research is to analyze the peculiarities of forming the interaction of the motor and cognitive functional systems of the brain in children, adolescents and young men while performing information tasks of different modality and complexity.

\section{Materials and Methods}

The success and speed of performing isolated and combined motor and cognitive tasks of different modality (using shapes or words) were studied in 116 right-handed individuals who had agreed to participate in the investigation. The study was conducted in accordance with the Helsinki Declaration (adopted in Helsinki, Finland, in 1964 and revised in October 2000 in Edinburgh, Scotland) and approved by the Ethics Committee of the Cherkasy National University. The motor task involved the time registration of motor reaction with the left or right hand on the signals of different modality in the go/go/go mode. The cognitive task consisted of a neurophysiological test in the go/nogo/go mode with random (by 33\%) presentation of the signals with different modality that had to be reacted to (go); the nogo stimulus was not to be reacted to (Makarenko et al., 2011).

The experimental task involved 6 tests determining: $I-$ the number of mistakes and motor reaction speed for the right hand on different shapes; II - the same for the left hand; III - the number of mistakes and motor reaction speed for the right hand for words; IV - the same for the left hand; $\mathrm{V}$ - the number of mistakes and the speed of the combined motor and cognitive reaction in switching attention to shapes for the right and left hand; VI - the same for words. While performing the motor task (test I, II, III and IV), the investigated individual had to press and release the control panel button with one hand in the go/go/go mode with maximum speed when any signal appeared on the monitor screen. While performing tests $\mathrm{V}$ and $\mathrm{VI}$, the investigated individual had to perform the task in the goL/nogo/goR mode differentiating motor and cognitive components, determining signal modality, figure shape (test $\mathrm{V}$ ) or word meaning (test VI), switching attention constantly, composing the programme selectively, reacting with the left or right hand and inhibiting the reaction. The shapes of a circle, triangle or square were presented on a screen in test V. It was necessary for the participants to determine the modality and stimulus quickly, to switch attention (cognitive component), to press the control panel button quickly (motor task): on a square with the right hand (goR), on a circle with the left hand (goL), and not to react to a triangle (nogo). Test VI was similar to the previous one, but the cognitive component consisted in the differentiative reaction to a word about animals (goR), plants (goL), and inanimate objects (nogo). As with the previous four tasks, the participant had to perform tasks correctly in tests V and VI, to press buttons quickly without making mistakes.

Experiments were conducted on the computer system of IBM PC AT 386 type by specially designed methodology and "Diagnost-1" program (Makarenko et al., 2011). 30-second differentiation of signals in the optimal mode of their presentation was used for test load. The order and time of 30 presented signals varied and was random. The time of signal exposure was $0.7 \mathrm{sec}$.; the pause duration changed randomly by the algorithm of the software. Each of the three signals appeared 10 times and did not repeat itself. $\mathrm{X}, \mathrm{SD}, \mathrm{Cv}, \mathrm{SE}$ and the number of mistakes were registered after performing the task. The obtained data were statistically processed using ANOVA. The Tukey test with the Bonferroni correction was used to determine significant differences $(\mathrm{P}<$ 0.05 ) between the mean values obtained for each age group, the modalities of the signal and the reaction of the hand. The results in the tables are presented as $\mathrm{x} \pm \mathrm{SD}(\mathrm{x} \pm$ standard deviation). Correlation analysis was performed using the Pearson coefficient (r).

\section{Results}

Age peculiarities of performing motor tasks in the go/go/go mode for the signals of different modality. The comparative characteristics of successful task performance (the number of mistakes) in the investigated age groups while processing information in the go/go/go mode for the signals of different modality (shapes/words) with the left and right hand did not show significant differences $(\mathrm{P}>0.05)$. Reliable differences were not found in the results fo the number of mistakes made while processing information of imaginative and verbal signals in the go/go/go mode for the left and right hand in the investigated age groups $(\mathrm{P}>0.05)$. Statistically significant differences were found in the number of mistakes in the investigated groups of the children aged 7-8 and the young people aged $19-20(\mathrm{P}<0.001)$.

The analysis of dynamics of the motor reaction speed in the go/go/go mode in the groups of children, adolescents and young men for the left and right hand found a clear difference of the reaction time between the investigated age groups (Table 1).

\section{Table 1}

Reaction time $(\mathrm{x} \pm \mathrm{SD}, \mathrm{ms})$ to the signals of different modality for the left and right hand in the go/go/go mode in the individuals of different age

\begin{tabular}{lcccc}
\hline Age & $\begin{array}{c}\text { Reaction time } \\
\text { to image sig- } \\
\text { nals with the } \\
\text { left hand } \\
\text { (Test I) }\end{array}$ & $\begin{array}{c}\text { Reaction time } \\
\text { to image sig- } \\
\text { nals with the } \\
\text { right hand } \\
\text { (Test II) }\end{array}$ & $\begin{array}{c}\text { Reaction time } \\
\text { to verbal sig- } \\
\text { nals with the } \\
\text { left hand } \\
(\text { Test III) }\end{array}$ & $\begin{array}{c}\text { Reaction time } \\
\text { to verbal sig- } \\
\text { nals with the } \\
\text { right hand } \\
\text { (Test IV) }\end{array}$ \\
\hline $7-8(\mathrm{n}=25)$ & $329.8 \pm 51.1^{\mathrm{a}}$ & $325.1 \pm 53.9^{\mathrm{a}}$ & $359.0 \pm 62.0^{\mathrm{a}}$ & $357.2 \pm 60.0^{\mathrm{a}}$ \\
$11-12(\mathrm{n}=28)$ & $285.4 \pm 27.5^{\mathrm{b}}$ & $279.8 \pm 29.6^{\mathrm{b}}$ & $312.8 \pm 44.7^{\mathrm{b}}$ & $311.9 \pm 61.0^{\mathrm{b}}$ \\
$15-16(\mathrm{n}=30)$ & $263.0 \pm 31.1^{\mathrm{bc}}$ & $260.2 \pm 28.4^{\mathrm{bc}}$ & $279.6 \pm 34.1^{\mathrm{c}}$ & $266.1 \pm 26.2^{\mathrm{c}}$ \\
$19-20(\mathrm{n}=33)$ & $241.0 \pm 24.7^{\mathrm{c}}$ & $253.3 \pm 26.3^{\mathrm{c}}$ & $243.1 \pm 17.7^{\mathrm{d}}$ & $250.1 \pm 26.3^{\mathrm{c}}$ \\
\hline
\end{tabular}

Note: different letters denote reliable differences age groups for pairwise comparison on Bonferroni using the criterion of Tukey $(\mathrm{P}<0.05)$.

Statistically significant differences in the speed of motor reaction in the go/go/go mode were not found in the participants aged 7-8 and 11- 
$12(\mathrm{P}>0.05)$. However, the reaction speed to shapes (test I and II) and words (test III and IV) for the right and left hand was reliably higher in adolescents aged $15-16$ and young men aged 19-20 $(\mathrm{P}<0.024)$. The analysis of the research results of different variants of motor tasks shows the gradual increase of the performance speed in information processing in the go/go/go mode in children, adolescents and young men. It is characteristic for both left and right hands and for the signals of different modality. The results of performing motor tasks were found to be higher in the young men aged 19-20 and adolescents aged 15-16, and lower in the children aged 7-8 and adolescents 11-12 $(\mathrm{P}<0.05)$. Tests III and IV used words for information processing, and there was some deterioration of speed results if compared with the motor reaction to shapes (test I and II). However, the differences in the time performance of the motor task for shapes and words for both right and left hands were found, but they did not reach the level of statistical significance $(\mathrm{P}>0.05)$. In tests I, II, III and IV, motor tasks were performed with the same speed and success of information processing for all the investigated age groups. The lack of statistical differences of success and speed of performing motor tasks for the left (test I and III) and right hand (test II and IV), and for the signals of different modality was found.

The results of success and speed in performing cognitive tasks in the goL/nogo/goR mode for the signals of different modality. The statistical analysis of success (the number of mistakes) of performing motor and cognitive tasks in the goL/nogo/goR mode showed significant differences between the investigated age groups (Table 2).

\section{Table 2}

Success ( $\mathrm{x} \pm \mathrm{SD}$, the number of mistakes) in performing cognitive task of different modality for the left and right hand in the goL/nogo/goR mode in the investigated groups of different age

\begin{tabular}{ccccc}
\hline Age & $\begin{array}{c}\text { Number of } \\
\text { mistakes on } \\
\text { image signals } \\
\text { with the left } \\
\text { hand } \\
(\text { Test V) }\end{array}$ & $\begin{array}{c}\text { Number of } \\
\text { mistakes on } \\
\text { image signals } \\
\text { with the right } \\
\text { hand } \\
(\text { Test V) }\end{array}$ & $\begin{array}{c}\text { Number of } \\
\text { mistakes on } \\
\text { verbal signals } \\
\text { with the left } \\
\text { hand } \\
(\text { Test VI) }\end{array}$ & $\begin{array}{c}\text { Number of } \\
\text { mistakes on } \\
\text { verbal signals } \\
\text { with the right } \\
\text { hand } \\
(\text { Test VI) }\end{array}$ \\
\hline $7-8(\mathrm{n}=25)$ & $2.0 \pm 1.1^{\mathrm{a}}$ & $1.9 \pm 1.4^{\mathrm{a}}$ & $9.2 \pm 3.2^{\mathrm{a}}$ & $7.8 \pm 3.8^{\mathrm{a}}$ \\
$11-12(\mathrm{n}=28)$ & $2.1 \pm 1.4^{\mathrm{a}}$ & $1.9 \pm 1.2^{\mathrm{a}}$ & $6.6 \pm 3.2^{\mathrm{b}}$ & $4.9 \pm 2.9^{\mathrm{b}}$ \\
$15-16(\mathrm{n}=30)$ & $1.5 \pm 1.1^{\mathrm{a}}$ & $1.8 \pm 1.1^{\mathrm{a}}$ & $3.9 \pm 3.5^{\mathrm{bc}}$ & $2.9 \pm 2.3^{\mathrm{b}}$ \\
$19-20(\mathrm{n}=33)$ & $1.6 \pm 1.2^{\mathrm{a}}$ & $1.1 \pm 1.1^{\mathrm{a}}$ & $4.7 \pm 3.2^{\mathrm{c}}$ & $3.1 \pm 2.0^{\mathrm{b}}$ \\
\hline
\end{tabular}

Note: see Table 1.

The analysis of results of the mistakes in the group of the individuals aged $19-20$ by Tukey's criterion found a statistically lower number of mistakes in the group of the young people aged 19-20 than in the children aged 7-8 $(\mathrm{P}<0.014)$. The success of performing motor and cognitive tasks while processing information in the goL/nogo/goR mode for the signals of different modality (shapes and words) were found to increase gradually in the children, adolescents and young men. Significant differences in the success in performing the combined task using image signals for the left and right hand were found only in the group of the young men aged 19-20 and children aged 7-8 ( $\mathrm{P}<0.043)$; and using verbal stimuli - the adolescents aged $15-16$ and children aged $7-8(\mathrm{P}<0.05)$. It should be noted that statistically significant differences in the number of mistakes under the condition of information processing with the use of the combined task for words (test VI) were lower in all the investigated groups if compared with the results in test $\mathrm{V}$ $(\mathrm{P}<0.05)$. Besides, statistically significant asymmetry of the success in processing information applying verbal signals was found in the adolescents aged 15-16 and the young men aged 19-20 $(\mathrm{P}<0.05)$. The number of mistakes for the right hand on verbal stimuli was statistically lower than for the left hand in most cases for the adolescents aged $15-16$ and the young men aged $19-20(\mathrm{P}<0.05)$.

The result of analysis of performance speed of cognitive task in the goL/nogo/goR mode showed statistically significant differences between the investigated age groups (Table 3). The speed of performance of cognitive tasks in tests V and VI was found to increase gradually (the time decreased) with age and achieved high results in the young men aged 19-20. Statistically significant differences of processing cognitive information were found in the age groups of the children aged 7-8, the adolescents aged 15-16 and the young men aged 19-20 ( $\mathrm{P}<0.05)$. Low values of the speed performance of the combined task on imaginative and verbal signals for the left and right hand were found in the children aged 7-8. It should be noted that statistically significant differences of the speed results of processing information using the combined task for the verbal signals were found at the ages of 11-12, 15-16 and 19-20 if compared with the children aged 7-8 $(\mathrm{P}<0.05)$. These age differences for the imaginative signals were found only at the ages of 15-16 and 19-20 $(\mathrm{P}<0.05)$. The results show that the speed of task performance gradually increases and the reaction time decreases during processing of cognitive imaginative and verbal information in children, adolescents and young men.

\section{Table 3}

Speed of reaction $(\mathrm{x} \pm \mathrm{SD}, \mathrm{ms})$ to the signals of different modality for the left and right hand in the goL/nogo/goR mode in the investigated individuals of different age

\begin{tabular}{lcccc}
\hline Age & $\begin{array}{c}\text { Reaction time } \\
\text { to image sig- } \\
\text { nals with the } \\
\text { left hand } \\
(\text { Test V) }\end{array}$ & $\begin{array}{c}\text { Reaction time } \\
\text { to image sig- } \\
\text { nals with the } \\
\text { right hand } \\
(\text { Test V) }\end{array}$ & $\begin{array}{c}\text { Reaction time } \\
\text { to verbal sig- } \\
\text { nals with the } \\
\text { left hand } \\
\text { (Test VI) }\end{array}$ & $\begin{array}{c}\text { Reaction time } \\
\text { to verbal sig- } \\
\text { nals with the } \\
\text { right hand } \\
\text { (Test VI) }\end{array}$ \\
\hline $7-8(\mathrm{n}=25)$ & $511 \pm 60^{\mathrm{a}}$ & $516 \pm 46^{\mathrm{a}}$ & $707 \pm 110^{\mathrm{a}}$ & $693 \pm 75^{\mathrm{a}}$ \\
$11-12(\mathrm{n}=28)$ & $460 \pm 68^{\mathrm{b}}$ & $476 \pm 61^{\mathrm{b}}$ & $663 \pm 80^{\mathrm{ab}}$ & $624 \pm 63^{\mathrm{b}}$ \\
$15-16(\mathrm{n}=30)$ & $428 \pm 42^{\mathrm{c}}$ & $404 \pm 36^{\mathrm{c}}$ & $612 \pm 47^{\mathrm{bc}}$ & $575 \pm 41^{\mathrm{c}}$ \\
$19-20(\mathrm{n}=33)$ & $398 \pm 62^{\mathrm{c}}$ & $417 \pm 51^{\mathrm{c}}$ & $623 \pm 67^{\mathrm{bc}}$ & $578 \pm 57^{\mathrm{c}}$ \\
\hline
\end{tabular}

Note: see Table 1 .

The analysis results by Tukey's criterion shows that statistically significantly lower values of the reaction time were found for the speed of performing cognitive tasks using image signals (Test $\mathrm{V}$ ) than verbal signals (Test VI) $(\mathrm{P}<0.05)$. These speed peculiarities of performing cognitive tasks were found for the left and for the right hand. Besides, the reaction speed for the verbal signals with the right hand was statistically higher (reaction time was less) than for the left hand. Processing verbal information with the right hand was faster than the left hand in the adolescents aged 11-12, 15-16 and the young men aged 19-20. In these age groups, statistically significant differences of reaction speed were found for the left and right hand $(\mathrm{P}<0.05)$. In the age group of 7-8, these differences in the reaction time for the left and right hand to the verbal signals were found, but they did not reach the level of statistical significance $(\mathrm{P}>0.05)$. It should be noted that the comparison of the speed of performing complex cognitive tasks on imaginative signals in the goL/nogo/goR mode (Test V) in the group of 7-8 and 11-12 year olds did not find differences of the mean values of the reaction time for the left and right hand $(\mathrm{P}>0.05)$.

The research shows that the reaction speed of the investigated individuals of different age while performing motor tasks ranges from $241 \pm$ 25 to $338 \pm 71 \mathrm{~ms}$, and cognitive tasks from $398 \pm 62$ to $709 \pm 102 \mathrm{~ms}$. As should be expected, these indicators were low in the children aged 7-8; further, with age, gradual increase of the performance speed was found for both tasks to its maximum value in the young men aged 19 20 (Table 1,3). Since the speed characteristics for the motor and cognitive brain system increase simultaneously in the ontogenesis, there is a need to calculate the correlation coefficients between speed characteristics of motor and cognitive reactions in the investigated age groups. Statistically significant correlation of functional interaction of motor and cognitive brain systems was found by the indicators of the speed of performing the offered informative tasks on image and verbal stimuli in the young men aged 19-20 and the adolescents aged 15-16, if compared with the children aged 7-8 and the adolescents aged 11-12 (Fig. 1).

The correlation analysis of the speed of processing imaginative information in the motor go/go/go and cognitive goL/nogo/goR tests for the investigated different age groups shows that the interaction between these systems is intensified with age. There is no correlation for image signals in the motor and cognitive brain system in the children aged 7-8 $(\mathrm{r}=0.21 ; \mathrm{P}>0.05)$ and the adolescents aged 11-12 $(\mathrm{r}=0.19 ; \mathrm{P}>0.05)$. This correlation is intensified and reaches statistically significant values in the adolescents aged $15-16(\mathrm{r}=0.38 ; \mathrm{P}<0.047)$ and the young men aged 19-20 $(\mathrm{r}=0.36 ; \mathrm{P}<0.049)$. The analysis of the speed results of 
information processing in the cognitive brain system for the verbal signals shows significant correlation between the investigated indicators in the age groups of $11-12(\mathrm{r}=0.38 ; \mathrm{P}<0.043), 15-16(\mathrm{r}=0.43 ; \mathrm{P}<$ $0.027)$ and $19-20(\mathrm{r}=0.41 ; \mathrm{P}<0.028)$ if compared with the research results on the speed of information processing in the motor task $\mathrm{go} / \mathrm{go} / \mathrm{go}$. There is no statistically significant correlation between speed characteristics of information processing in the cognitive brain system for the verbal signals and the research results of the speed of information processing in the goL/nogo/goR mode $(\mathrm{r}=0.19 ; \mathrm{P}>0.05)$. These facts can point out that motor automatism coincides with a high cognitive resource and can be used as a prognostic supportive factor for activities with high informative loads.

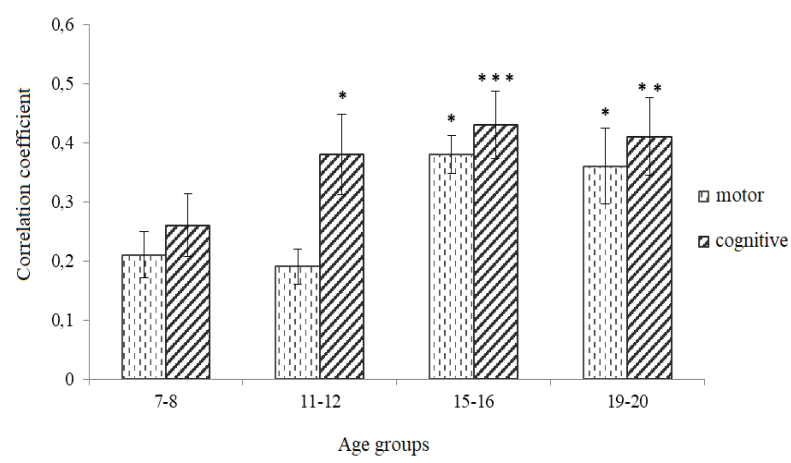

Fig 1. Correlation coefficient (r) of speed of processing information in the motor and cognitive brain systems on presenting image and verbal signals in the investigated individuals of different age: 7-8 (n

$=25), 11-12(\mathrm{n}=28), 15-16(\mathrm{n}=30), 19-20(\mathrm{n}=33)$;

* - significant correlation $(\mathrm{P}<0.05)$ for image signals in the age groups of 15-16, 19-20 and verbal signal in the age group of $11-12 ; * *$ - significant correlation $(\mathrm{P}<0.01)$ for verbal signals

in the age groups of $19-20 ; * * *$ - significant correlation

$(\mathrm{P}<0.001)$ for verbal signals in the age groups of $15-16$

Gradual statistically significant decrease in the number of mistakes and the increase in speed of performing different variants of motor and cognitive tasks in the goL/nogo/goR mode were found in the children, adolescents and young men. Age changes in the success and speed of performing different variants of the combined tasks in the goL/nogo/goR mode are dependent on signal modality. The investigated indicators are higher in the tasks with shapes and lower for words. Statistically significant asymmetry was found for the left and right hand by the number of false reactions and the speed of performing the combined test using verbal signals in the adolescents aged 15-16 and the young men aged 19-20. This asymmetry was not found for the shapes and words for the age group of the children aged 7-8. Statistically significant differences for the left and right hand were not found in the success and speed of performing the combined test using image signals for the age groups of children and the adolescents aged 15-16. At the same time, the asymmetry for the left and right hand while differentiating shapes in the goL/nogo/goR mode was found in the age group of 19-20.

\section{Discussion}

According to the literature data, the speed of performing motor tasks depends on the type, form, modality of the signal and the complexity of the task (Hazeltine et al., 2006; Lyzohub et al., 2018). Visual images (geometric shapes) and verbal signals (word meaning) addressed to different signal systems and afferent channels were used in this study. Tests I, II, III and IV gave participants the task to react as quickly as possible by pressing the panel button first with the left hand, and then with the right hand on any signal without defining its modality, shape type or word meaning (only the motor component). The success of performing the task, the number of false reactions and the reaction speed to the signals of different modality with the left or right hand in the go/go/go mode was the same in peers, which shows the participa- tion of the same basic neurophysiological mechanisms (Kostandov, 2010; Ivanitsky et al., 2013). The results of performing motor tasks were found to be higher in the young men aged 19-20 and the adolescents aged 15-16 and lower in the children aged 7-8 and adolescents aged 11-12, which is explained by the formation of psychophysiological functions in the ontogenesis (Farber et al., 2009).

We expected a decrease of the performance speed in tests III and IV where the words were used to process information if compared with the motor reaction on shapes (Test I and II). However, the differences in the time of motor task performance and number of mistakes for shapes and words for both right and left hand were found not to reach the level of statistical significance $(\mathrm{P}>0.05)$. Previously, we have shown that the process of processing sensory-motor information in the go/go/go mode includes, at least, two functional systems, namely, sensory and motor (Makarenko et al., 2011; Lyzohub et al., 2018). Motor tasks might be carried out without the special participation of cortical processes in tests I, II, III and IV. The lack of statistical differences in the success and speed of motor task performance for the left hand (Test I and III) and the right hand (Test II and IV) and for the signals of different modality may show a small proportion of cortical functions.

Processing cognitive three-stimulus information depends on the choice of the mode for signal presentation. Thus, in tests V and VI, the speed and success of performance significantly decreased (the time of reaction and the number of mistakes increased) using the differentiation of goL/nogo/goR; and particularly for the verbal signals if compared with the motor tasks in the go/go/go mode. The success and speed of performing different variants of the motor tasks in the go/go/go mode was higher in all age groups than in the conditions of the combined motor and cognitive tasks while differentiating goL/nogo/goR. The speed of performing the combined motor and cognitive task of goL/nogo/goR using geometric shapes was, on average, by $64 \%$ lower for the left hand and by $49 \%$ lower for the right hand than in the motor Test I and II $(\mathrm{P}<$ 0.05 ). At the same time, the reaction speed decreased, on average, by $113 \%$ for the right hand and $151 \%$ for the left while performing the combined task using words if compared with the results of motor test III and IV $(\mathrm{P}<0.05)$. These tasks are likely to cover more complex cognitive processes of the higher divisions of the central nervous system, in addition to the sensory and motor components of information processing, characterized by the distribution and switching attention, the mobilization of memorable traces, the differentiated analysis and the formation of an action programme (Donker et al., 2007; Doumas et al., 2009). Thus, in addition to the sensory and motor components of information processing in the goL/nogo/goR mode, the cognitive component is added, being the ability to analyze signals, to differentiate shapes (Test $\mathrm{V}$ : circle, square, triangle) or the meaning of the words (Test VI: plants, animals, inanimate objects), to switch attention, to match stimuli in memory, to draw up an action plan, to react quickly with the left (goL) or right (goR) hand, or to restrain the motor response (nogo).

It should be noted that the participants performed the tasks with signal meaning of shapes quicker and more successful than with verbal stimuli irrespective of age. The statistically significant decrease in performance speed of the combined tasks and the increase in the number of mistakes were found in the goL/nogo/goR mode both on shapes and, particularly, words in compared with the isolated performance of the motor task in the go/go/go mode $(\mathrm{P}<0.05)$. It is necessary to point out that the decrease of the performance speed of the combined task and the manifestation of manual lateralization effect, related to the predominant processing of verbal information in the left hemisphere, was found in Test $\mathrm{V}$ using goL/nogo/goR mode for the imaginative signals and in Test VI - for verbal signals (Sperry, 1980; Luria, 2004; Kostandov, 2010). The results of task performance for both hands in the participants with right-hand domination show that the reaction speed in the combined motor and cognitive test was quicker with the right hand than with the left one. So, the time of differentiating words in the adolescents and young men for the left hand was, on average, by $46 \mathrm{~ms}$ longer than for the right hand $(\mathrm{P}<0.05)$. The faster reaction time for the right hand in the right-handers indicates an easier transmission of information from the left hemisphere to the right one and is different for the time of the callosal delay. It shows the peculiarities of realizing the mechanisms of 
interhemispheric integration (Tretiak et al., 2016). The fact that the right hand performed the task with verbal signals faster compared with the left hand can be explained in the following way. The information presented was simultaneously received in each hemisphere, where the selection and various conversions took place separately for verbal and imaginative systems of short-term memory. Since these systems have clear lateralization of the hemisphere (imaginative signals are more lateralized to the right hemisphere, and verbal signals - to the left), and the central processor of each hemisphere takes part in maintaining attention and decision making (Rusalova, 2003), the participant had to quickly analyze, compare the information in memory regarding its compliance with the instructions, and then compile a programme of action and perform a motor act. In our study, the mental step for the left hemisphere, in the case of presenting verbal signals (information from the left hemisphere is transmitted to the right hand), was by $46 \mathrm{~ms}$ (13\%) higher than for the right hemisphere (information from the right hemisphere is transmitted to the left hand). These results show the leading part of the central processor of the left hemisphere in processing verbal signals ( $\mathrm{Si}-$ monov et al., 1995).

The most interesting results were obtained in the study of the speed of performing motor and cognitive tasks on verbal stimuli (Test VI). The speed of performing the combined motor and imaginative cognitive task in the three-stimulus paradigm of $\mathrm{goL} / \mathrm{nogo} / \mathrm{goR}$ was quicker (Test V) than for the verbal signals (Test VI) $(\mathrm{P}<0.05)$. We can make assumptions about the mechanisms of such differences. First of all, the analysis of the imaginative signals is performed by the work of the first signal system, which includes a large number of cortical and subcortical structures characterized by high reliability (Sperry, 1980; Bernstein, 2003; Horak, 2006; Maurer et al., 2006). In contrast, more phylogenetically young verbal functions are provided with the work of the second signal system, which is more corticalized in the front areas, less stable and has a limited neurophysiological resource (Luria, 2004). In addition, verbal functions are characterized with relative rigidity, being the inability to switch quickly from one action goL to another one goR or nogo due to the low level of their automation and the involvement of additional neural networks (Kalnysh \& Shvets, 2012; Ivanitsky et al., 2013). These facts are also confirmed by the results of our research showing the increase in the number of mistakes and the variability of indicators for the combined tests, especially with the use of words, indicating the complexity of the neural networks, instability of the functional system, reducing the level of the mobilization of functional reserves including attention and memory (Kalnysh \& Shvets, 2012; Korobeynikov et al., 2013). However, imaginative signals are characterized with higher flexibility, ease of switching attention and their high automation.

Secondly, the neurophysiological mechanism that explains the decrease of the speed and success of information processing for the combined motor and cognitive test in the goL/nogo/goR paradigm may be interference. There might be a difference in the time of excitation for the different brain parts while performing each of the components of motor and cognitive tasks. It is precisely such spatial-temporal diversity of the brain activity while performing dual tasks that was described earlier (Zhavoronkova et al., 2011). At the same time, our results show that the left-hemispherical asymmetry prevailed in the individuals with righthand dominance while processing the combined, motor and cognitive information. However, there are no such differences in case of performing motor tasks for any modality. Asymmetry in all age groups is weakly expressed for the combined tasks with imaginative stimuli and statistically significant for the verbal signals. If we take into account the above data, it will become clear why the cerebral hemispheres in children, adolescents and young people work more symmetrically while processing imaginative stimuli. At the same time, the perception of the verbal stimulus and the formation of the response to it, lead to the appearance of asymmetry. Such a "switch" in the work of the hemispheres may be aimed at increasing the efficiency of the task performance, reducing the likelihood of mistakes in case of a conflict state between three streams of information goL, goR and nogo (there is an interference). It should be noted that the organization of the cognitive system in the young men aged 19-20 is in "asymmetric" mode irrespective of image or verbal signal which is perceived and analyzed, if compared with the children aged 8-9. The obtained data may show the fact that control for neurointegration of motor and cognitive objective and verbal signals in the right-handed individuals is carried out in the left hemisphere, and may take part in the participation of proton-activated channels that selectively modulate the activity of the GABA-ergic system, depending on the modalities of the sensory signal (Storozhuk \& Krishtal, 2017).

Thirdly, the lack of statistical differences in the speed of performing the combined task on shapes for the left and right hand (Test V) may show that in the cerebral cortex, there is a neuro-integration characterized with information synthesis, the focus of interaction for a large number of neurons (networks/columns) discharging in the same rhythm. Different parts of the brain work synchronically in these conditions (Ivanitsky et al., 2013). We can assume that the focus of interaction for image signals is established in the neural networks. Reaction speed to verbal signals for the left and right hand (Test V) decreases significantly; there is asymmetry characterized with discoordination of excitatory and inhibitory processes. It may show that there is no neurointegration of motor and cognitive systems, and there is interference in this case. The difference in the performance time of the cognitive task for the left and right hand shows the predominance of inhibition in the right hemisphere that significantly deteriorates the time of motor reaction for the left hand (Stroop, 1935; Scherder, 2008; Howe, 2009; Scarpina \& Tagini, 2017). In our research, the interference effect was expressed more for the cognitive brain system.

Correlation analysis shows that in the ontogenesis, the interaction of motor and cognitive brain systems while processing information of different modality in children, adolescents and young men increases gradually. A closer functional relationship of motor and cognitive brain systems was found in the indicators of speed and success in performing both tasks in the young men aged 19-20, the adolescents aged 15-16 and 11-12 than for the children aged 7-8. In most cases, the participants with high speed of performing cognitive tasks were characterized with reliably higher indicators of motor reactions. In the combined motor and cognitive test, the number of the brain parts working synchronically was found to increase dramatically, and the number of independent parts decreased (Lyvanov, 1989). At the same time, the number of correlations increases depending on the complexity of the motor and cognitive task. These results are an experimental evidence of the fact that the speed characteristics of the cognitive brain system are connected with the motor system due to the improvement of the functional interaction in neural networks of the cerebral cortex and the improvement of the neuromuscular apparatus of the investigated individuals. Thus, we can assume that in most cases, the higher the speed of the cognitive processes, the quicker the information processing in the motor system. And conversely, those participants who were found to have low time indicators of information processing for the cognitive system were characterized with low level of the motor motional actions. In our opinion, the speed of information processing in the brain's cognitive systems is not simply the difference in the time of information processing or separate brain operation but the result of complex integrative activity of the brain, inter-central interaction, functional maturation of the associative zones regulating complex cognitive and motor activity with subsequent conjugation of morphological and functional changes in the neural networks of the cerebral cortex, as well as the improvement of the neuromuscular apparatus (Makarenko \& Lyzohub, 2011).

Obviously, the interaction of motor and cognitive brain systems while processing information of different complexity and modality, which gradually increases with age, can be explained by the heterochronous maturation of various brain structures that provide processing of complex mental load. Children are known to undergo noticeable changes in the development of the precentral area of the cerebral cortex with the improvement of intercentral interactions and, in general, at the age of 17-20, the functional maturation of associative zones regulating complex motor activity reaches its peak, followed by morphological and functional changes in the neural networks of the cerebral cortex, and the improvement of the neuromuscular apparatus (Farber et al., 2009; Makarenko \& Lyzohub, 2011; Bekhtereva et al., 2015). In our research, the correlation between quantitative criteria of time for all age groups of adolescents and young men shows the fact that the task per- 
formance of processing verbal information in differentiating positive (goL and goR) and inhibitory (nogo) stimuli occurs with the participation of complex analytical synthetic activity of the higher parts of the central nervous system and with the appropriate involvement of different systems and intersystem interaction in structural and functional organization of the brain activity. The revealed facts indicate that motor automatism coincides with high cognitive resource and can be used as a prognostically favourable factor for the activities with high informative loads.

The results of this study broaden the theoretical understanding of the plasticity of the nervous system and the interaction of the motor and cognitive brain systems while processing information of different complexity and modality, which gradually increases with age. The experimental data make it possible to generalize that one of the possible mechanisms underlying the enhancement of the interaction of cognitive and motor functions of the young men aged 19-20 in comparison with the children aged 7-8 is the closer inter-hemisphere, multi- and interneural bonds of different systems and the brain networks. These intermodal bonds develop in the ontogenesis and as the result of long-term training sessions. Psychophysiological results of the research show quicker and higher quality processing of stimuli in the young men aged 19-20 than in the adolescents and children, which is likely to be due to closer inter-hemisphere interaction, possibly due to the increased myelination of commissural fibers.

Thus, this study extends our understanding of the interaction of motor and cognitive brain systems with respect to the mechanisms for processing information of different complexity and modality. This work is a solid basis for further scientific research on neuro-ontogenesis mechanisms, the influence on the motor and cognitive sphere of an individual with the aim of the differentiated application of this knowledge in the development of rehabilitation measures and methods for theoretical and practical medicine and pedagogy.

\section{Conclusions}

We studied age-specific features of the interaction of motor and cognitive brain systems in children, adolescents and young men during fast and error-free processing and differentiating of image and verbal information in the goL/nogo/goR and go/go/go modes. This formulation of the experiment allowed us to assess the role of motor and cognitive brain systems in the organization of the integrative brain activity in conditions close to real ones. The success and speed of performing tasks in processing and differentiating information were found to depend on the modality of the signal, the mode of presenting stimuli and the age of the investigated individuals. The interaction of motor and cognitive systems was found to increase gradually with age in children, achieving its highest level of development in the young men aged 19-20. The participants of all age groups processed information more quickly and successfully in the motor brain system than in the cognitive one. The cognitive task on presenting image signals was found to be performed better by the young men than adolescents and children. Interference and lefthemisphere asymmetry were found in the children while performing tasks in processing verbal information in the mode of goL/nogo/goR differentiation. The following information parameters were established: the number of mistakes and reaction time with the left and right hand to the signals of different modality and complexity correlating with the characteristics of success and speed of performing complex information tasks. The presented experimental model of three-stimulus cognitive task can be used for the prognostic assessment of mental activity opportunities of students and people working in the conditions of complex information load, as well as the deficiency of cognitive reserves or restrictions in various forms of neurodegenerative diseases, age dementia, as well as obtaining information on the state of fatigue and correction of the neocortex in fatigue and unfavourable conditions.

It should be stressed that in our opinion, the obtained experimental data show the complex role of the motor and cognitive brain systems in processing various types of information; and that their interaction changes in individuals of different age and achieves the highest level in young men. Although we have found out some peculiarities and regularities of the interaction of motor and cognitive brain systems in onto- genesis while processing information of different modalities and complexity, the assessment of the nature of complex influences on the real physiological function and the mechanisms of such interaction need further neurophysiological research. Undeniably, the mechanisms of such interaction of the motor and cognitive brain systems require further neurophysiological studies using the basic rhythms of EEG and neuroimaging on CT, MRI. It is necessary to find out what mechanisms underlie the performance of three-stimulus motor and cognitive tasks and what the role of different brain parts and time distribution is, while performing tasks. It is possible that the age peculiarities of spatialtemporal diversity for different brain parts and EEG rhythms underlie neurophysiological mechanisms and occur in participants while performing cognitive and motor tasks.

\section{References}

Bekhtereva, V., Craddock, M., \& Miiller, M. M. (2015). Attentional bias to affective faces and complex IAPS images in early visual cortex follows emotional cue extraction. Neuroimage, 112, 254-266.

Bernstein, N. A. (2003). Sovremennyie issledovaniya po fiziologii neyronnogo protsessa [Contemporary studies on the physiology of the neural process]. Smysl, Moscow (in Russian).

Dempsey, J. A., \& Morgan, B. J. (2015). Humans in hypoxia: A conspiracy of maladaptation? Physiology, 30(4), 304-316.

Donker, S., Roerdink, M., Greven, A., \& Beek, P. (2007). Regularity of center-ofpressure trajectories depends on the amount of attention invested in postural control. Experimental Brain Research, 181(1), 1-11.

Doumas, M., Rapp, M. A., \& Krampe, R. T. (2009). Working memory and postural control: Adult age differences in potential for improvement, task priority, and dual tasking. The Journals of Gerontology. Series B, Psychological Sciences and Social Sciences, 64, 193-201.

Farber, D. A., Bezrukikh, M. M., \& Sonkin, V. D. (2009). Vozrastnaya fiziologiya (fiziologiya razvitiya rebenka) [Age physiology (physiology of child development)]. Izdatelskyi Center, Moscow (in Russian).

Fraizer, E., \& Mitra, S. (2008). Methodological and interpretive issues in posturecognition dual-tasking in upright stance. Gait and Posture, 27(2), 271-279.

Furley, F., \& Memmert, D. (2010). Differences in spatial working - memory as a function of team sports expertize: The Corsi block-tapping task in sport psychological assessment. Perceptual and Motor Skills, 110(3), 801-808.

Glantz, S. (1998). Biomeditsinskaya statistika [Biomedical statistics]. Practika, Moscow (in Russian).

Haggard, P., \& Cockbum, J. (1998). Dividing attention between cognitive and motor tasks in neurological rehabilitation. Neuropsychologycal Rehabilitation, 8, 155-170.

Hazeltine, E., Ruthruff, E., \& Remongton, R. (2006). The role of input and output modality pairings in dual-task performance: Evidence for content-dependent central interference. Cognitive Psychology, 52(4), 291-345.

Hiraga, C. Y., Garry, M. I., Carson, R. G., \& Summers, J. J. (2009). Dual-task interference: Attentional and neuropsychological influences. Behavioural Brain Research, 205(1), 291-345.

Horak, F. B. (2006). Postural orientation and equilibrium: What do we need to know about neural control of balance to prevent falls? Age and Ageing, $35(2), 7-11$.

Howe, E. (2009). Hemispheric interaction in simple reaction time as a function of handedness. The Plymouth Student Scientist, 2(1), 90-107.

Ivanitsky, A. M., Portnov, G. V., \& Martynova, O. V. (2013). Kartirovanie mozga v slovesnom i prostranstvennom myishlenii [Brain mapping in verbal and spatial thinking]. Journal of Higher Nervous Activity, 63(6), 677-686 (in Russian).

Kalnysh, V. V., \& Shvets, A. V. (2012). Vliyanie intensivnoy kruglosutochnoy smennoy rabotyi na nadezhnost rabotyi operatorov [Effect of intense 24-hour shift work on reliability of operators' activity]. Human Physiology, 38(3), 8191 (in Russian).

Kamenskaya, V. G., Tomanov, L. V., \& Russak, Y. A. (2015). Peculiarities of sensory-motor response in girls of 14-17 years with different rates of sexual maturation. Indian Journal of Science and Technology, 29, 1-9.

Korobeynikov, G. V., Pristupa, O., Korobeinikova, L., \& Briskin, Y. (2013). Otsinka psykhofiziolohichnykh staniv u sporti [Assessment of psychophysiological states in sports]. LDUFK, Lviv (in Ukrainian).

Kostandov, E. A. (2010). Vliyanie konteksta na plastichnost poznavatelnoy deyatelnosti [Influence of the context on the plasticity of cognitive activity]. Human Physiology, 36(5), 19-28 (in Russian).

Kostenko, S. S., \& Lokteva, R. K. (2000). Otsinka aktyvnosti pershoi ta druhoi syhnalnykh system liudyny [Evaluation of activity of the first and second signaling systems of a person]. Bulletin of the Kiev University, Biology, 32, 31-34 (in Ukrainian). 
Low, K. A., Leaver, E. E., Kramer, A. F., Fabiani, M., \& Gratton, G. (2009). Share or complete? Load-dependent recruitment of prefrontal cortex during dual-task performance. Psychophysiology, 46(5), 1069-1079.

Luria, A. R. (2004). Osnovy neyropsihologii [Basics of Neuropsychology]. Prosveshcheniye, Moscow (in Russian).

Lyvanov, M. N. (1989). Prostranstvenno-vremennaya organizatsiya potentsialov i sistemnoy aktivnosti mozga [Spatial-temporal organization of potentials and systemic activity of the brain]. Nauka, Moscow (in Russian).

Lyzohub, V. S., Chernenko, N. P., Palabiyik, A. A., \& Bezkopulna, S. V. (2018). Sposib vyznachennia rozumovoi pratsezdatnosti za umovy pererobky informatsii z riznoiu shvydkistiu prediavlennia podraznykiv [Method of definitions of mental performance during processing of information with different speed of presentation of stimuli]. Cherkasy University Bulletin, Biological Sciences Series, 1, 70-80 (in Ukrainian).

Makarchuk, N., Maksimovich, K., Kravchenko, V., \& Kryzhanovskii, S. (2011). Modifications of EEG activity related to perception of emotionally colored, erotic, and neutral pictures in women during different phases of the ovulatory (menstrual) cycle. Neurophysiology, 42(5), 362-370.

Makarenko, M. V., \& Lizohub, V. S. (2011). Ontohenez psykhofiziolohichnykh funktsii liudei [Ontogenesis of psychophysiological functions of people]. Vertykal, Cherkasy (in Ukrainian).

Makarenko, M. V., Lizohub, V. S., Galka, M. S., Yuhimenko, L. I., \& Khomenko, S. M. Patent 96496, State Service for Intellectual Property of Ukraine, MPC A 61B5/16. Method of psychophysiological evaluation of the functional state of the auditory analyzer. No 2010-02225; stated 01.03.2010; published 10.11.2011. Bul. No 21.

Maurer, C., Mergner, R., \& Peterka, R. (2006). Multisensory control of human upright stance. Experimantal Brain Research, 171, 231-250.

Rusalova, M. N. (2003). Funktsionalnaya asimmetriya mozga i emotsiy [Functional asymmetry of the brain and emotions]. Successes of Physiological Sciences, 34(4), 93-112 (in Russian).
Scarpina, F., \& Tagini, S. (2017). The stroop color and word test. Frontiers in Psychology, 8, 557-562.

Schulz, K., Mueller, A., \& Koelsch, S. (2011). Neural correlates of strategy use during auditory working memory in musicians and non-musicians. The European Journal of Neuroscience, 33(1), 189-196.

Simonov, P. V., Rusalova, M. N., \& Preobrazhenskaya, L. A. (1995). Faktory novizny i asimmetrya mozga [Novelty factors and brain asymmetry]. Journal of Higher Nervous Activity, 45(1), 12-18 (in Russian).

Sperry, R. W. (1980). Mind-brain interaction: Mentalism, yes; dualism, no. Neuroscience, 5, 195-206.

Storozhuk, M., \& Krishtal, O. (2017) ASICs may affect GABAergic synapses. Oncotarget, 8(26), 41788-41789.

Stroop, J. (1935). Studies of interference in serial verbal reactions. Experimental Psychology, 18(6), 643-662.

Tretiak, T. O., Dregval, I. V., \& Severinovskaya, O. V. (2016). Analiz funktsionalnykh vzaiemodii kortykalnykh zon z vizualnym typom myslennia liudyny [Analysis of functional interactions of cortical zones with the visual-shaped type of human thinking]. Bulletin of Biology and Medicine, 131, 292-297 (in Ukrainian).

Van der Elst, W., Van Boxtel, M. P., Van Breukelen, G. J., \& Jolles, J. (2006). The stroop color-word test: Influence of age, sex, and education; and normative data for a large sample across the adult age range. Assessment, 13(1), 62-79.

Verbraggen, F., \& Logan, G. D. (2008). Automatic and controlled response inhibition: Associative learning in the go ne-g; and stop-signal paradigms. Journal of Experimental Psychology, General, 137(4), 649-672.

Zhavoronkova, L. A., Kuptsova, S. B., Zharikova, A. V., Kushnir, E. M., \& Mikhalkova, A. (2011). Harakteristika izmeneniy reaktivnosti EEG pri vyipolnenii dvoynyih zadaniy u zdorovyih sub'ektov (dobrovolnyiy posturalnyiy kontrol i raschet) [Characteristics of EEG reactivity changes during the performance of dual tasks in healthy subjects (voluntary postural control and calculation)]. Human Physiology, 37(6), 688-699 (in Russian). 